\title{
Surgical considerations for 'intrinsic' brainstem gliomas: Proposal of a modification in classification
}

\author{
V. S. Mehta, P. S. Chandra ${ }^{1}$ Pankaj Kumar Singh ${ }^{1}$, Ajay Garg ${ }^{2}$, G. K. Rath ${ }^{3}$ \\ Paras Hospitals, Gurgaon, Departments of ${ }^{1}$ Neurosurgery, ${ }^{2}$ Neuroradiology and ${ }^{3}$ Radiotherapy, All India Institute of Medical Sciences, \\ New Delhi, India
}

\author{
Address for correspondence: \\ Dr. P. Sarat Chandra, \\ Department of Neurosurgery, \\ Room 710, $7^{\text {th }}$ Floor, \\ Cardio Neurosciences Center, \\ All India Institute of Medical \\ Sciences, New Delhi - 10 029, India. \\ E-mail: saratpchandra@gmail.com
}

DOI: $10.4103 / 0028-3886.53272$

\begin{abstract}
Background: Brainstem gliomas are highly heterogeneous tumors both in their clinical manifestation and in their pathology. Despite significant advances in the surgery for brainstem gliomas many aspects of this pathology are still unclear Objective: To evaluate the clinical, radiological and surgical outcome of 40 focal 'intrinsic' brainstem gliomas and propose a surgical strategy-oriented classification. Materials and Methods: A total of 40 focal 'intrinsic' ("expanding variety") tumors have been operated over a period of 8.5-years (January 1998-June 2007). Our criteria included patients with (1) well-defined gadolinium enhancing tumor; (2) relatively long duration of symptoms ( $>$ six months) and (3) good neurological functional status and independent for all activities of daily living. The cutoff size of $2 \mathrm{~cm}$ was not rigidly adhered to. Results: The 'intrinsic' brainstem tumors were classified into three types: Expanding, diffuse infiltrative and pure ventral varieties. Only patients with expanding variety of brainstem gliomas were subjected to surgery, mean age 19.2 years (range $4-55$ years) and male to female ration mean: $3: 2$ ). The tumor location included pons $(n=19)$, midbrain $(n=13)$ and medulla $(n=8)$. Surgical approaches included midline suboccipital $(n=28)$, retromastoid $(n=7)$, subtemporal $(n=3)$ and supracerebellar-infratentorial $(n=2)$. Thirty-two cases with 'diffuse infiltrative' and 'pure ventral' variety were given radiotherapy only. Histology pathology revealed pilocytic variety $(n=10)$, Grade II $(n=17)$ and Grade III $(n=13)$. There was one death in the surgical series (due to aspiration). Complications included meningitis $(n=2)$, wound infection $(n=1)$, chest infection $(n=5)$ and transient mutism $(n=1)$. Follow-up ranged from 3-68 months. Overall, 36 improved /remained same and three worsened in their clinical status at the time of discharge. Conclusion: The surgical management of intrinsic brainstem tumors presents a surgical challenge; radical excision yielded a good outcome in the majority of cases. The authors propose a classification system for 'intrinsic' brainstem tumors for defining surgical strategy.
\end{abstract}

Key words: Brainstem, focal, gliomas, intrinsic

\section{Introduction}

Brainstem gliomas are highly heterogeneous tumors both in their clinical manifestation and in their pathology. They occur commonly in children, accounting for $10-20 \%$ of all central nervous system tumors and they may occur in adults too. ${ }^{[1]}$ The term "brainstem glioma" is an imprecise descriptive word and suggests that the behavior of all such tumors is likely to be the same, which may not be true. Prognosis in these tumors may be directly related to grade of tumor and location..$^{[1-7]}$ Amongst all the types of brainstem gliomas, there has been relatively sparse description in the literature on the "intrinsic" variety, ${ }^{[3-10]}$ particularly those falling 
under WHO Grade I category, with well-defined focal pathology but within the brainstem axis i.e. "intrinsic". While these tumors present a surgical challenge, a radical removal, if not followed by any significant complications, may yield a good long-term outcome in the majority of cases.

Despite significant advances in the surgery for brainstem gliomas many aspects of this pathology are still unclear: (1) Inspite of several proposed classifications mostly based on anatomical location, ${ }^{[5,11-14]}$ the surgical plan is still difficult to decide in many cases. In this aspect the classification proposed by Choux et al., ${ }^{[15]}$ perhaps comes closest in defining a surgical plan; (2) The difference between diffuse and large focal intrinsic brainstem gliomas is not clearly distinguished in most of the classifications. Thus sometimes it is possible that a large focal intrinsic benign tumor may not be subjected to surgery and sent for radiotherapy directly; (3) It is usually not possible radiologically to determine whether the tumor is benign or malignant. A stereotactic biopsy too may have limitation, it may pick up a benign portion of a malignant tumorn or vice versa. Thus a more important approach would be to try and remove the tumor as radically as possible provided the radiological image reveals such an opportunity, preferably by surgeon who has sufficient experience in this area.

The aim of this study was to review our experience in the surgery for 'intrinsic' brainstem gliomas, all operated by a single senior experienced surgeon and examine the outcome in relation to the surgical approach and nature of the imaging and to propose a simple working classification for defining surgical strategy.

\section{Materials and Methods}

Only the 'intrinsic' brainstem tumors were included in this retrospective study. By the term 'intrinsic' the authors indicate that the tumor is still contained within the boundaries of the brainstem parenchyma without an exophytic component. Only those cases operated by the senior author were included in this series. We excluded all other operated cases to avoid surgeon's bias and also to exclude learning curve period. Surgery was done in the patients with following clinical characteristics: (1) tumor well demarcated on gadolinium MR imaging; (2) relatively long clinical history (> six months); (3) clinically well-preserved -independent for all activities of daily living; and (4) tumor size $<2 \mathrm{~cm}$ was not strictly adhered to ${ }^{[5,6]}$ Patients were subjected to direct radiotherapy (without surgery) if the boundary of the tumor was ill-defined on magnetic resonance imaging (MRI), the tumor had a pure ventral location and/or patient had a rapid onset of clinical symptoms. These criteria have been based on the senior author's experience over 25 years [Table 1] and the same criteria also formed the basis of the proposed classification.

(1) Expanding variety: Characteristics - (a) well-delineated lesion as seen on gadolinium contrast MRI located posteriorly, posterolaterally or ventrolaterally; (b) slow evolution of neurological deficits over a period of more than six months; (c) well preserved functional status, independent for all activities of daily living.

\begin{tabular}{|c|c|c|c|}
\hline $\begin{array}{l}\text { Type of brainstem } \\
\text { glioma }\end{array}$ & Features & Comparison with other classifications & Surgery \\
\hline [A] Intrinsic only & $\begin{array}{l}\text { The tumor is well within the brainstem axis } \\
\text { without any breach of the parenchyma }\end{array}$ & & \\
\hline $\begin{array}{l}\text { [A.1] Expanding } \\
\text { variety }\end{array}$ & $\begin{array}{l}\text { - Well-delineated on Gd-MRI } \\
\text { Slow progression of clinical symptoms } \\
\text { ( }>6 \text { months) } \\
\text { Good preservation of motor function } \\
\text { with independent activities of daily } \\
\text { living } \\
\text { - Size may be }>2 \mathrm{~cm}\end{array}$ & $\begin{array}{l}\text { Epstein et al. }{ }^{[11]} \\
\text { Focal }[<2 \mathrm{~cm}]^{*} \text {, cervicomedullary } \\
\text { Stroink et al. }{ }^{[12]} \\
\text { Group III, IV } \\
\text { Choux et al. }{ }^{[15]} \\
\text { Type II, IV } \\
{ }^{*} \text { tumors }>2 \mathrm{~cm} \text { could still be expanding variety } \\
{ }^{* *} \text { based on contrast enhancement and radiology } \\
\text { only; clinical features not taken into consideration } \\
{ }^{* * *} \text { based more on anatomical localization, clinical } \\
\text { features not mentioned again }\end{array}$ & $\begin{array}{l}\text { Yes } \\
\text { Radical excision }\end{array}$ \\
\hline $\begin{array}{l}\text { [A.2] Diffuse infiltra- } \\
\text { tive variety }\end{array}$ & $\begin{array}{l}\text { - No margin of delineation on Gd-MRI } \\
\text { - Rapid progression of symptoms }\end{array}$ & $\begin{array}{l}\text { Epstein et al. }{ }^{[11] *} \text { : diffuse } \\
\text { Stroink et al. }{ }^{[12] * *}: \text { Ila } \\
\text { Choux et al. }{ }^{[15]}: \text { Type I } \\
{ }^{*} \text { Tumor looking focal but }>2 \mathrm{~cm} \text { are still considered } \\
\text { diffuse } \\
{ }^{* *} \text { Clinical features not taken into account }\end{array}$ & No \\
\hline $\begin{array}{l}\text { [A.3] Ventrally } \\
\text { located }\end{array}$ & - Pure ventral location & $\begin{array}{l}\text { May be kept as focal in other classifications, but } \\
\text { authors prefer not to operate in view of the difficult } \\
\text { location and associated high risk of complications }\end{array}$ & No \\
\hline
\end{tabular}

Note that classification for exophytic tumors is the same as proposed by earlier authors but has been included here to provide completeness 
(2) Infiltrating diffuse variety: Characteristics - (a) margins between the tumor and the surrounding parenchyma not well-differentiated, (b) short duration illness with rapid progression of neurological symptoms.

(3) Ventrally located tumors: Characteristics - (a) ventral location of tumor without any lateral and posterolateral extension; (b) These tumors have been included in a different subset because of the 'very difficult to access' surgical location. It has been felt by the authors to best leave these tumors alone as surgical intervention may cause more complications.

According to the authors only the patients with 'expanding variety' should be subjected for surgery. If surgery was undertaken, a radical removal was preferred. Radiotherapy was given only if the tumor was found to be malignant on histology.

\section{Patient population}

A total of 40 cases with 'expanding variety' of brainstem glioma were operated over a 8.5-year period (January 1998-June 2007) personally by the senior surgeon (VSM). These patients were compared with 28 patients with 'diffuse infiltrative' tumors and 4 patients with 'pure ventral' tumors who were subjected to radiotherapy only (July 2003 - December 2006).

\section{Demographic and clinical profile}

Expanding variety

The mean age was 19.2 years (range $4-55$ yrs) and male: Female ratio was 3:2. The age distribution was: 13 in 21-40 years, 11 in 11-20 years, 10 in < 10 years, and 6 in above 40 years. The clinical features included cerebellar signs $(n=28)$, pyramidal signs $(n=27)$ [hemiparesis $(n=10)$, quadriparesis $(n=5)$, only pyramidal signs in the form of brisk deep tendon reflexes and up going plantar $(n=12)$, but all were ambulant], ocular palsy $(n=19)$, V nerve involvement $(n=13)$, facial palsy $(n=12)$, lower cranial nerve palsy $(n=9)$, Horner's $(n=4)$ and sensorineural deafness $(n=2)$. Nine patients had chronic headache. One patient lapsed into altered sensorium a day earlier to admission; underwent an emergency shunt for obstructive hydrocephalus. The duration of clinical features ranged from 2-96 months (at the time of presentation to the first physician) with a mean of 13.6 months.

\section{Diffuse infiltrative and pure ventral variety}

The mean age was 5.2 years; (range 0.9-16 years). Of the 32 patients, 17 had symptoms onset less than three months, 12 had symptoms onset within six months and the remaing 2 had symptom onset between 6-12 months. The clinical features included pyramidal signs in 26 [hemiparesis in 16 , quadriparesis in 19, 11 were dependent for all activities of daily living], and cerebellar signs in 16 cases.

\section{Investigations $Z$}

Contrast MRI was performed in all the patients. For the expanding variety, the tumor location was pons in 19, midbrain in 13, and medulla in 8 . In diffuse infiltrative variety, contrast MRI showed uniform enlargement of the brainstem axis without any differentiation between the tumor and the surrounding parenchyma [Figure 1], while MRI in the 'pure ventral' variety revealed ventral location of the tumor without any lateral extensions.

\section{Management}

Surgery was performed in all the 40 patients with 'expanding variety' of brainstem gliomas. Surgery was performed in sitting $(n=20)$, prone $(n=10)$, lateral $(n=7)$, and supine $(n=3)$ positions. The sitting position was preferred for dorsal midbrain or upper pontine lesions. The prone position was preferred in dorsally situated lower pontine, medullary or cervicomedullary lesions. Lateral position was preferred in ventrolateral lesion of lower pons while supine position was used for ventrolateral midbrain or thalamic lesions. A midline suboccipital approach with or without vermian split was most commonly preferred (28) followed by retromastoid suboccipital cerebello-pontine angle approach $(\mathrm{n}=7)$, subtemporal approach $(\mathrm{n}=3)$ and supracerebellar infratentorial approach in two cases. Microsurgical techniques along with adjuvant instruments like the micro-CUSA (Valley Lab/ Sonoca), tissue vaporizer (Japan Medical Dynamic Marketing Inc), and intraoperative evoked potentials and brain mapping were used wherever indicated. In all the patients, a thin layer of brainstem parenchyma covered the surface. Cranial nuclei mapping was performed before incising the parenchyma over the floor of the fourth ventricle by the operating surgeon. This was performed in the following manner. Initially, the floor of the fourth ventricle was screened with bipolar electrodes using a $0.1-1 \mathrm{~mA}$ single stimulus or at $10 \mathrm{~Hz}$ frequency runs at $50-400 \mathrm{~ms}$. The responses were monitored using electromyography leads implanted within the orbicularis occuli, oris and the tongue. The lower cranial nerves were monitored by noting the hemodynamic/cardiac responses. The area with maximal response with least stimulus was identified to be the area closest to or at the cranial nerve nuclei. Incision over the parenchyma was always given over the thinnest part away from the nuclei if any. If there was decline of response during resection, the surgeon usually waited with saline irrigation before testing the response again and proceeding further with surgery. A radical resection (total or near total resection) was attempted in most patients. A thin layer of tumor tissue was left if it appeared not separable from the surrounding normal structure. All the patients were started on methylprednisolone just before making an incision on the brainstem and this was continued for 24-48 h. All patients were electively ventilated with sedation for $24-48 \mathrm{~h}$. 


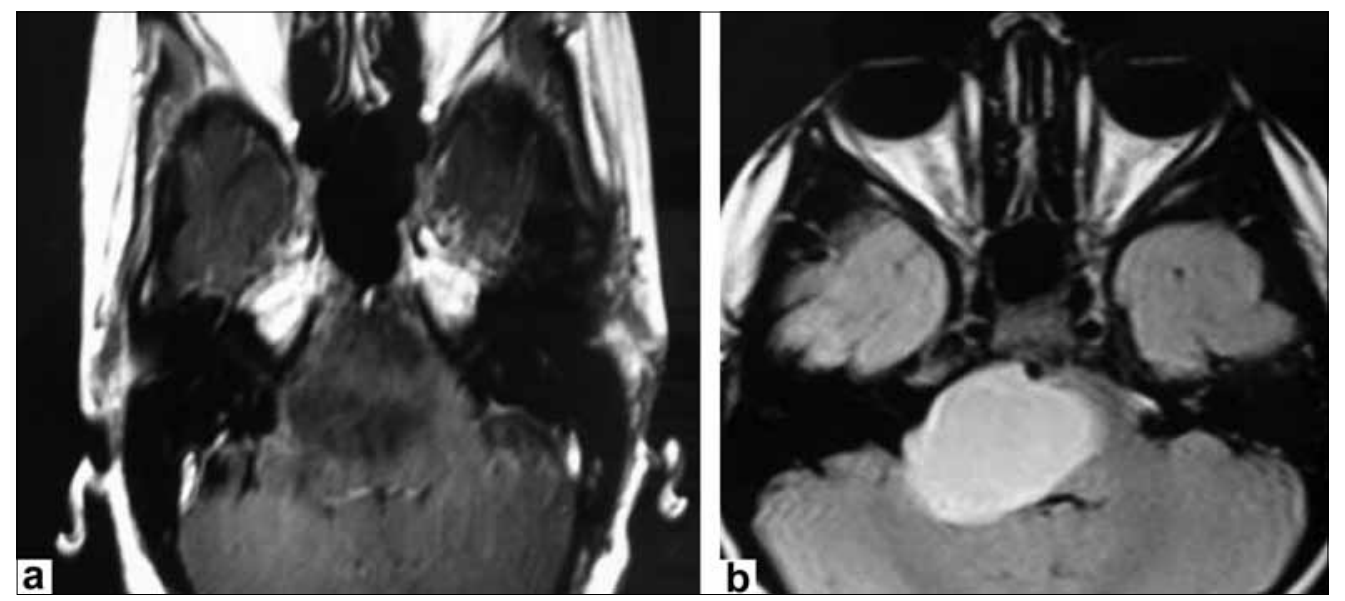

Figure 1: MRI axial sections showing (a) "diffuse infiltrating type" as compared to "expanding type" (b) of brainstem glioma. In the latter, the tumor is well-differentiated from the surrounding parenchyma and even though is well beyond the cut off size of $\mathbf{2} \mathrm{cm}$ (to be classified as a focal tumor) would be (according to the authors) still amenable for surgical excision

All cases of diffuse infiltrative $(n=28)$ and pure ventral $(n=4)$ brainstem gliomas ( $\mathrm{n}=32$ cases) were directly subjected to radiotherapy (fractionated with Co60).

\section{Results}

\section{Expanding variety}

Histology revealed pilocytic astrocytomas in 10, Grade II in 17 and Grade III in 13. There was one death, due to aspiration. This patient had preoperative lower cranial palsy with the tumor location in the ponto-medullary axis and biopsy revealed a Grade III glioma. Postoperative MRI revealed a focal variety, however, at surgery it was found to be a diffuse variety with no clear-cut demarcation. One patient (one of the early cases) underwent a partial decompression. Following surgery, the patient had a poor respiratory reserve. There was deterioration of motor power after $24 \mathrm{~h}$ while on ventilator. Computed tomography (CT) scan showed swelling of the residual tumor with no hemorrhage. Patient was taken up for surgery and the tumor was decompressed radically. Patient improved following surgery, and she did require tracheostomy and tracheostomy care for four weeks. Complications included meningitis (two), wound infection (one), chest infection (five) and transient mutism (one). All these patients improved with appropriate treatment. Follow-up ranged from 3-68 months. Overall 35 patients improved or remained the same and three patients worsened in their clinical status at the time of discharge and one patient (as described above) after a transient deterioration improved.

Follow-up MRIs performed in 28 patients revealed no residual tumors in 23 patients [Figures 2 and 3] and a very minimal residual tumor in five patients. All the patients with Grade I tumor are being followed up without radiotherapy while the patients with Grade II and III tumors were subjected to radiotherapy (either conventional $\mathrm{Co}^{[60]}$ or stereotactic radiotherapy). Sixteen patients, 14 with Grade I or II tumor, had a follow-up of more than two years. In one patient the ocular palsy improved during follow-up [Figure 3]. Three patients with pilocytic astrocytomas had follow up for three, five and six years respectively without recurrence. Seven patients, four pilocytic astrocytomas; three, Grade II, had a follow-up ranging from 11-21 months. Of the 13 patients with Grade III gliomas, only three had a follow-up for up to two years following radiotherapy and chemotherapy. The maximal follow-up available for the other 17 patients was up to six months after which they were lost for follow-up. A Kaplan Meier curve is depicted showing the probability of survival for this group of patients [Figure 4].

\section{Diffuse infiltrative and pure ventral varieties}

Three patients were lost for follow-up after just one month following radiotherapy. Seventeen patients had a follow-up till three months, six till six months, four till nine months and only two had a follow-up greater than one year. It must be mentioned here that all these patients were treated on outpatient basis only. In India follow-up is generally difficult, particularly if the prognosis explained is grim and the patient's attendants do not report deaths. There were four patients in the 'pure ventral' group. In view of the location of the tumor these patients were deemed surgically inaccessible and were categorized under diffuse variety. They too received radiotherapy without a biopsy. Contrary to this group, surgical patients have a better follow-up as the patient and thier attendants are keen to have continued optimal treatment. Thus it would be difficult to comment on the actual survival of the patients based on these figures [Figure 4]. 


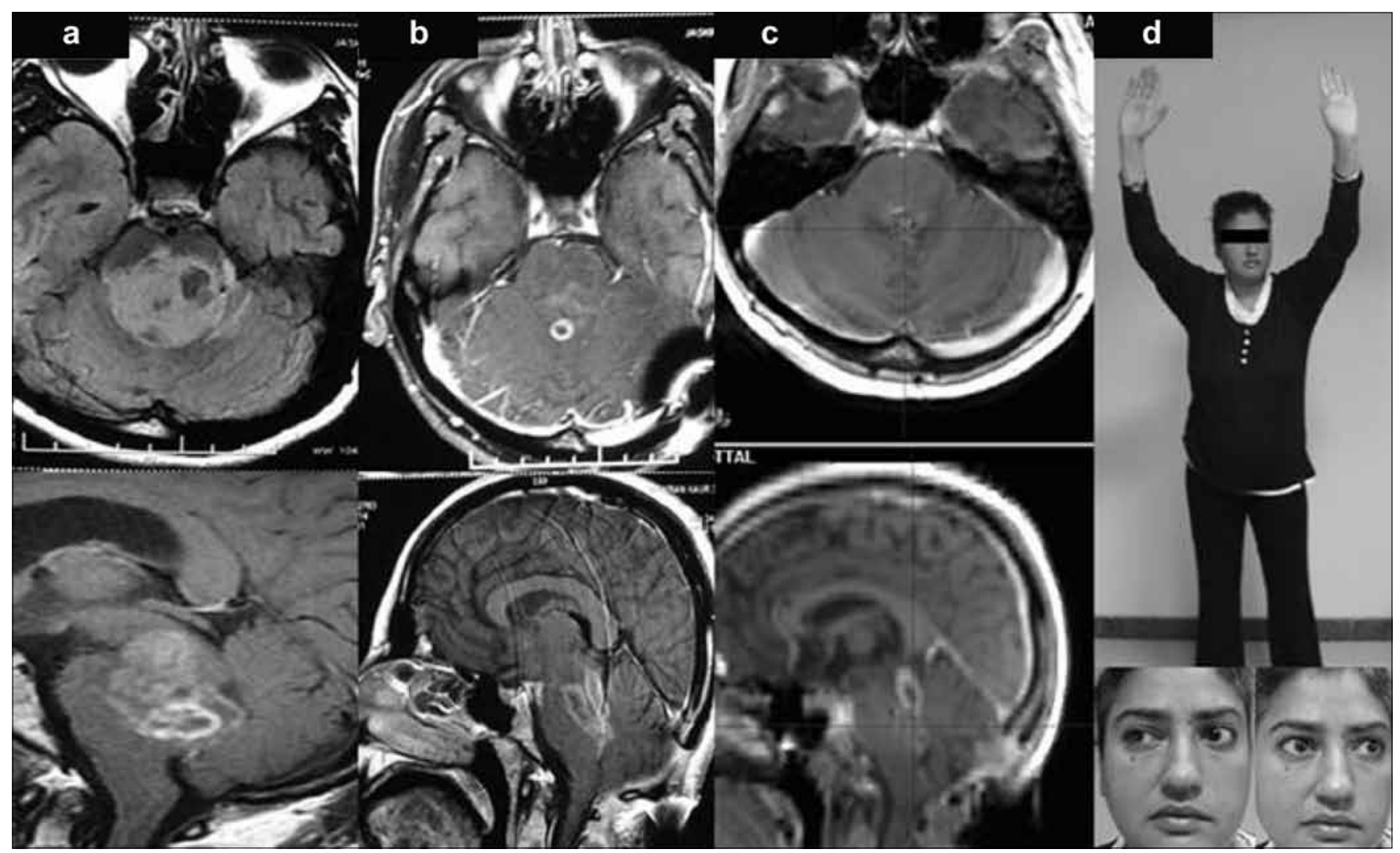

Figure 2: MRI showing a large "expanding type" of tumor (a) situated dorsally, heterogeneously enhancing with contrast with a cystic component. Note the well-defined margins and the size well beyond $2 \mathrm{~cm}$. The patient underwent a radical excision. Histopathology showed a Grade II tumor with a low MIB labeling index of $\mathbf{8 \%}$. Postoperative imaging at three months (b) showed a small residual tumor. In view of the relatively higher MIB labeling index, the patient underwent radiotherapy. The tumor was still of the same size at the time of the latest follow-up (c). The patient at six months of follow-up (d) shows preserved oculomotor movements with Grade I facial palsy. There has been no deterioration of the patient's clinical status, and like most of the patients with 'expanding type' of tumors was independent for all activities of daily living before surgery

\section{Discussion}

Various classifications of brainstem tumors have been proposed. . $23,5,-7,9,16,17]^{\text {Epstein }}{ }^{[5,6,10,17]}$ and others ${ }^{[7,8,16,18]}$ have defined focal tumors as well-circumscribed masses with a diameter less than $2 \mathrm{~cm}$. Any tumor larger than $2 \mathrm{~cm}$ is considered as diffuse tumor. We, however, included even tumors greater than $2 \mathrm{~cm}$ within the focal tumor category provided the lesion was well-defined and involved a focal area of the brainstem and the patient's clinical features also suggested a focal pathology and relatively slowly progressive course. In addition we included only those patients with minimal neurological deficits and good functional life, able to attend all activities of daily living. In all the patients an attempt was made to perform excision as radically as possible. In instances where differentiation between the tumor and the surrounding normal parenchyma was difficult we left a thin rim of tumor. We have not taken tumor grading into consideration as some of our patients with Grade III tumor had clinical and MRI criteria to be included under well defined focal 'intrinsic' lesion. We feel that the definition of 'diffuse' should include only those tumors involving the brainstem axis homogenously with no differentiation between normal brainstem and the tumor. Based on our experience with these tumors, we propose a new classification [Table 1]. We recommend surgery only for the 'expanding variety' of tumors. This classification has some advantages: (1) It provides a simple surgical strategy whether or not to operate 'pure' intrinsic tumors; (2) The classification does not emphasize on the $2 \mathrm{~cm}$ cut-off to differentiate between focal and diffuse tumors, This allows to consider surgery in some of the subset of tumors initially classified as 'diffuse' if they fulfill other criteria of expanding variety of tumor; (3) This classification combines both biological and imaging characteristics.

The surgery for focal 'intrinsic' tumors remains one of the most challenging in neurosurgery. While radical excision is advised for these lesions, outcome is very much depends on the experience of the surgeon, completeness of tumor excision, and postoperative complications. Epstein ${ }^{[5]}$ et al., in their experience of treating 66 children with intrinsic brainstem tumors concluded that focal solid or cystic tumors are generally benign and should subjected to radical excision and this can result in a long-term survival. Qi-Wu Xu${ }^{[8]}$ et al., have described 


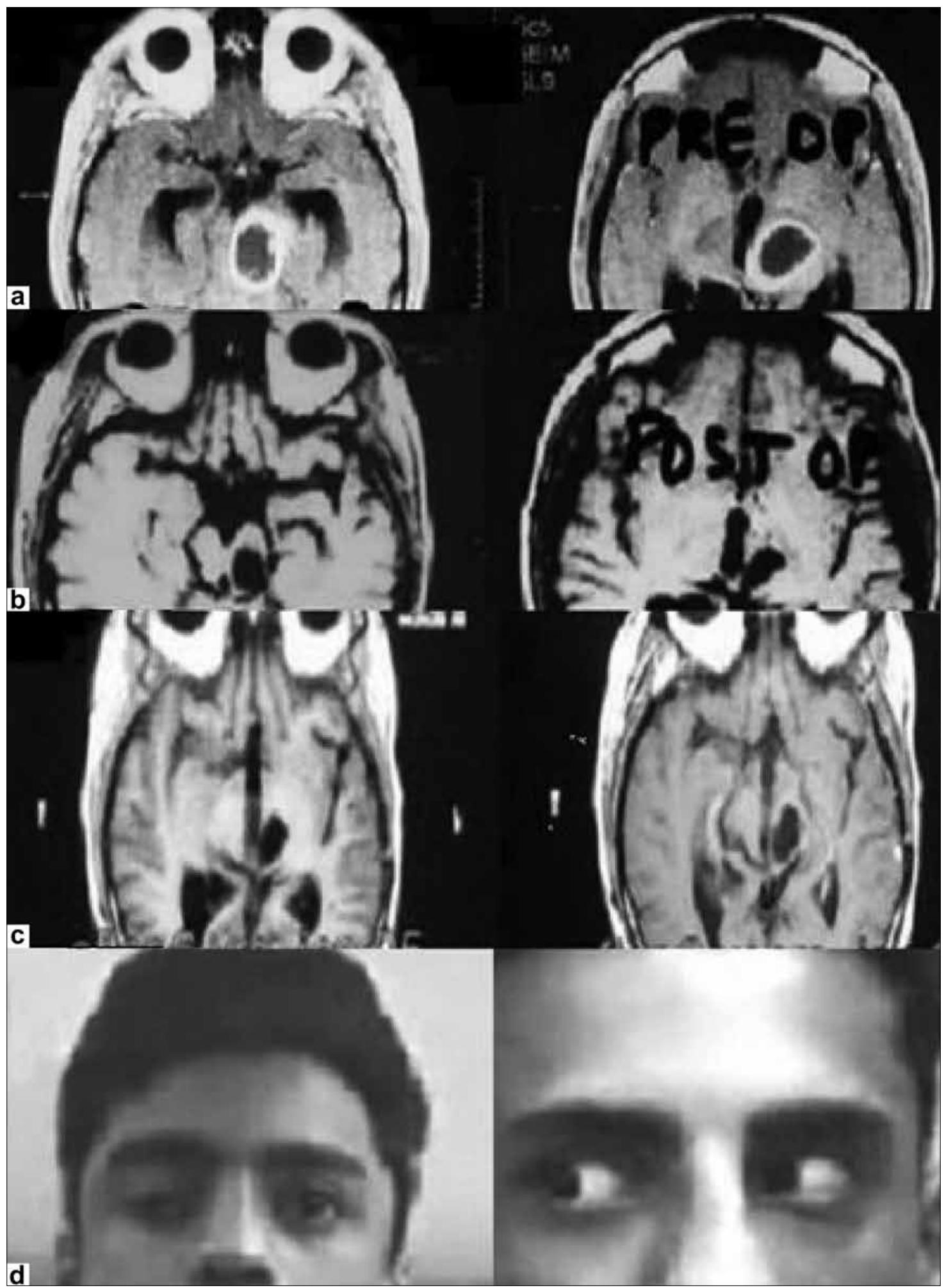

Figure 3: MRI shows another example of an "expanding type" (a) of tumor located in the midbrain. The margin of the tumor is well-enhancing and within the brainstem axis. The patient underwent an attempted stereotactic biopsy followed by radiotherapy outside. The patient underwent a total excision (b; MRI-Gad enhanced at three months). No radiotherapy after surgery was given. A follow-up MRI (with contrast) six years (c) after surgery still showed no recurrence. The patient had right ptosis and ophthalmoparesis (d; left picture) immediately following surgery, which resolved at one year. Photo at six years (d; right picture) shows complete resolution of eye movements

22 cases of solid brainstem tumors. Radical resection was performed in 20 patients, 19 were gliomas (astrocytomas or ependymomas). The study also included a few tumors with exophytic components. There were complications in 10 cases and one death. About 17 cases improved at the time of discharge. They concluded that tumors showing a 


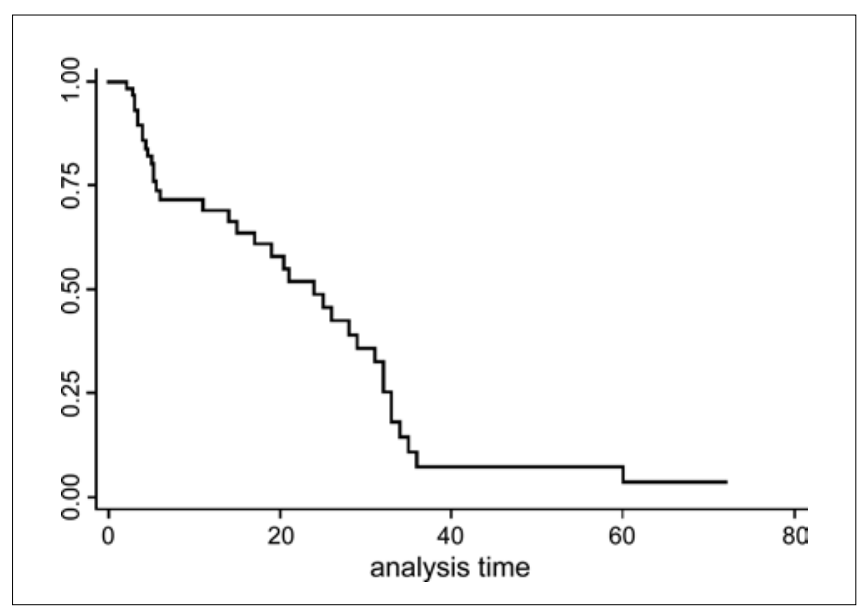

Figure 4: The curve shows the survival probability in the ' $Y$ ' axis versus the maximum duration of follow-up in the ' $X$ ' axis denoted in months for the patients who underwent radical surgery for expanding lesions [ $=40$ ]

focal solid nature on MRI should be subjected to a radical excision. Miyamoto et al., ${ }^{[9]}$ have recently described two patients with intrinsic midbrain pilocytic astrocytomas who had complete excision of the tumor and good long-term outcome without recurrence. Heffez et al., ${ }^{[7]}$ in their study have suggested the importance of a more aggressive approach in tumors, which appear focal and discrete on MRI. Apart from these studies, there have been few other reports ${ }^{[4,19,20]}$ on the radical resection of truly intra-axial brainstem gliomas. Most of them have described focal 'intrinsic' tumors as a part of their larger studies. In this series of highly selected 40 patients with expanding variety of brainstem tumor radical excision of the tumor was done by a single surgeon, which reduced the inter-surgeon bias. Overall, 35 patients improved or remained the same following surgery and three worsened. There was one death. One of the initial patient needed redo-surgery. Our experience suggests that these tumors need radical removal and is associated with good longterm outcome. Sixteen patients had more than two years follow-up. Two patients with pilocytic astrocytoma had follow-up for five and six years with no recurrence. One of the patient with ocular had complete improvement.

We attempted to compare the expanding variety brainstem tumor group with 32 patients, 28 diffuse infiltrative variety, and four pure ventral, variety brainstem tumor group who were subjected to direct radiotherapy. The limitations for this comparison were, the analysis was retrospective and the time-frame of the two groups was different. In spite of these limitations, a few differences stand out prominently between the two groups: The mean age of the expanding variety group was much higher than the diffuse infiltrative variety and pure ventral variety group (19.2 vs. 5.2 years; $\mathrm{P}<0.01$ ). The duration of symptoms was much shorter in the diffuse infiltrative variety and pure ventral variety group and clinical progression much more rapid. Eighty per cent of patients with diffuse infiltrative variety and pure ventral variety group subjected to direct radiotherapy had much severe pyramidal symptoms than those compared with the expanding variety $(67 \%)$. All these features suggest a more aggressive neurobiology for diffuse infiltrative and pure ventral varieties brainstem gliomas as compared with the expanding variety brainstem gliomas, These features may also corroborate the MRI morphology.

Several authors have suggested that partial resection or biopsy combined with postoperative radiation is effective in many cases of focal, tumors, particularl, pilocytic astrocytomas. ${ }^{[4,21]}$ However, recurrence up to $20 \%$ has been reported in the literature with this approach. ${ }^{[21]}$ Furthermore, malignant transformation has been reported as a significant sequel after partial resection. ${ }^{[22-24]}$ The other limitation with this approach will be not including the malignant part of the tumor in the resection ${ }^{[25]}$ One of our earlier patients deteriorated following partial removal possibly due to swelling of the residual tumor. While partial decompression may not cause such deterioration in exophytic tumors as these tumors have space to 'swell' outside the brainstem axis.

The identification of various subgroups of brainstem tumors has led to more rational treatment strategies and allows for a more accurate assessment of prognosis. The 'intrinsic' tumors with paucity of neurological signs are a distinct subgroup of brainstem tumors (expanding variety). Most of them are low-grade astrocytomas and are amenable to radical surgical resection but this should be performed by an experienced surgeon in a setup with adequate intraoperative and postoperative facilities. Surgical intervention in this subgroup of brainstem tumors is associated with an excellent long-term prognosis. This is in contrast to the diffuse infiltrative and pure ventral group which should be subjected to radiotherapy only.

\section{References}

1. Bruno L, Schut L. Survey of pediatric brain tumors, in American Association of Neurological Surgeons: Pediatric Neurosurgery. Surgery of the Developing Nervous System. New York: Grune and Stratton; 1982. p. 361-5.

2. Artigas J, Ferszt R, Brock M, Kazner E, Cervos-Navarro J. The relevance of pathological diagnosis for therapy and outcome of brain stem gliomas. Acta Neurochir Suppl 1988;42:166-9.

3. Hoffman HJ, Becker L, Craven MA. A clinically and pathologically distinct group of benign brain stem gliomas. Neurosurgery 1980;7:243-8.

4. Edwards MS, Wara WM, Ciricillo SF, Barkovich AJ. Focal brainstem astrocytomas causing symptoms of involvement of the facial nerve nucleus: Long term survival in six pediatric cases J Neurosurg 1994;80:20-5.

5. Epstein F, McCleary EL. Intrinsic brain-stem tumors of childhood: Surgical indications. J Neurosurg 1986;64:11-5.

6. Epstein F. Intrinsic brainstem tumors of childhood. In: Homburger F, editor. Progress in Experimental Tumor Research. Basel: Karger; 1987. 
p. 160-9.

7. Heffez DS, Zinreich SJ, Long DM. Surgical resection of intrinsic brain stem lesions: An overview. Neurosurgery 1990;27:789-98.

8. Xu QW, Bao WM, Mao RL, Jiang DJ, Yang GY. Surgical treatment of solid brain stem tumors in adults: A report of 22 cases. Surg Neurol 1997;48:30-6.

9. Miyamato S, Mikuni K, Yamada J, Takahasi A, Hashimoto N. Radical resection for intrinsic midbrain pilocytic astrocytoma: Report of two cases. Acta Neurochir 2005;147:93-7.

10. Epstein FJ, Farmer JP. Brain stem growth patterns. J Neurosurg 1993;78:408-12.

11. Epstein F. A staging system for brain stem gliomas. Cancer 1985;56:1804-6.

12. Stroink AR, Hoffman HJ, Hendrick EB, Humphreys RP, Davidson G. Transependymal benign dorsally exophytic brain stem gliomas in childhood: Diagnosis and treatment recommendations. Neurosurgery 1987;20:439-44.

13. Barkovich AJ, Krischer J, Kun LE, Packer R, Zimmerman RA, Freeman CR, et al. Brain stem gliomas: A classification system based on magnetic resonance imaging. Pediatr Neurosurg 1991;16:73-83.

14. Kaplan AM, Albright AL, Zimmerman RA, Rorke LB, Li H, Boyett JM, et al. Brainstem gliomas in children: A Children's Cancer Group review of 119 cases. Pediatr Neurosurg 1996;24:185-92.

15. Choux M, Lena G, Do L. Brainstem tumors. In: Choux M, Di Roceo C, Hockley A, editors. Pediatric Neurosurgery. New York: Churchill Livingstone; 2000. p. 471-91.

16. Fisher PG, Breiter SN, Carson BS. A clinicopathological reappraisal of brain stem tumor classification. Cancer 2000;89:1560-76.

17. Epstein F, Wiscoff JH. Intrinsic brainstem tumors in childhood: Surgical indications. J Neurooncol 1988;6:309-17.

18. Albright AL, Guthkelch AN, Packer RJ, Price RA, Rourke LB. Prognostic factors in pediatric brain-stem gliomas. J Neurosurg 1986;65:751-5.

19. Tomita T, Chou P, Reyes-Mugica M. IV ventricular astrocytomas in childhood: Clinicopathologieal features in 21 cases. Childs Nerv Syst $1998 ; 14: 537-46$

20. Bricolo A, Turazzi S, Cristophori L, Talacehi A. Direct surgery for brainstem tumors. Acta Neurochir (Suppl) Wien 1991;53:148-58.

21. Dirven CM, Mooij JJ, Molenaar WM. Cerebellar pilocytic astrocytoma: A treatment protocol based upon analysis of 3 cases and review of literature. Childs Nerv Syst 1997;13:17-23.

22. Alpers CE, Davis RL, Wilson CB. Persistence and late malignant transformation of childhood cerebellar astrocytoma: Case report. J Neurosurg 1982;57:548-51.

23. Casadei GP, Arrigoni GL, D'Angelo V, Bizzoero L. Late malignant recurrence of childhood cerebellar astrocytoma. Clin Neuropahol 1990;9:295-8.

24. Krieger MD, Gonzalez-Gomez I, Levy ML, McComb JG. Recurrence patterns and anaplastic changes in a long term study of pilocytic astrocytomas. Pediatr Neurosurg 1997;27:1-11.

25. Kuroiwas T, Ohta T, Tsutsumi A. Malignant pilocytic astrocytoma in medulla oblongata: Case report. Brain tumour Pathol 1999;16:81-5.

26. Eifel PJ, Cassady JR, Belli JA. Radiation therapy of tumors of the brainstem and midbrain in children: Experience of the Joint Center for Radiation Therapy and Children's Hospital Medical Center (19711981). Int J Radiat Oncol Biol Phys 1987;13:847-52.

27. Fischbein NJ, Prados MD, Wara W, Russo C, Edwards MS, Barkovich AJ. Radiologic classification of brain stem tumors: Correlation of magnetic resonance imaging appearance with clinical outcome. Pediatr Neurosurg 1996;24:9-23.

28. Kansal S, Jindal A, Mahapatra AK. Brain stem gliomas: A study of 111 patients. Indian J Cancer 1999;36:99-108.

29. Kyoshima K, Kobayashi S, Gibo H, Kuroyanagi T. A study of safe entry zones via the floor of the fourth ventricle for brain-stem lesions. J Neurosurg 1993;78:987-93.

30. Daube JR. Intraoperative monitoring of motor cranial nerves. In: Schramm J, Møller AR, editors. Intraoperative Neurophysiologic Monitoring in Neurosurgery. Berlin: Springer Verlag; 1991. p. 246-7.

31. Møller AR. Intraoperative monitoring of cranial motor nerves. In: Møller AR, editor. Evoked Potentials in Intraoperative Monitoring. Baltimore: Williams and Wilkins; 1988. p. 99-120

32. Strauss C, Romstöck J, Nimsky C, Fahlbusch R. Intraoperative identification of motor areas of the rhomboid fossa using direct stimulation. J Neurosurg 1993;79:393-9.

33. Pakisch B, Urban C, Slave I, Poier E, Stücklschweiger G, Oberbauer R, et al. Hyperfractionated radiotherapy and polychemotherapy in brainstem tumours in children. Childs Nerv Syst 1992;8:215-8.

Accepted on 26-04-2009

Source of Support: Nil, Conflict of Interest: None declared.

\section{Author Help: Online submission of the manuscripts}

Articles can be submitted online from http://www.journalonweb.com. For online submission, the articles should be prepared in two files (first page file and article file). Images should be submitted separately.

1) First Page File:

Prepare the title page, covering letter, acknowledgement etc. using a word processor program. All information related to your identity should be included here. Use text/rtt/doc/pdf files. Do not zip the files.

\section{2) Article File:}

The main text of the article, beginning with the Abstract to References (including tables) should be in this file. Do not include any information (such as acknowledgement, your names in page headers etc.) in this file. Use text/rtf/doc/pdf files. Do not zip the files. Limit the file size to $400 \mathrm{~kb}$. Do not incorporate images in the file. If file size is large, graphs can be submitted separately as images, without their being incorporated in the article file. This will reduce the size of the file.

3) Images:

Submit good quality color images. Each image should be less than $1024 \mathbf{~ k b ~ ( 1 ~ M B ) ~ i n ~ s i z e . ~ T h e ~ s i z e ~ o f ~ t h e ~ i m a g e ~ c a n ~ b e ~ r e d u c e d ~ b y ~ d e c r e a s - ~}$ ing the actual height and width of the images (keep up to about 6 inches and up to about 1200 pixels) or by reducing the quality of image. JPEG is the most suitable file format. The image quality should be good enough to judge the scientific value of the image. For the purpose of printing, always retain a good quality, high resolution image. This high resolution image should be sent to the editorial office at the time of sending a revised article.

4) Legends:

Legends for the figures/images should be included at the end of the article file. 